\title{
The Performance of Diesel Engine Fueled Diesel Oil in Comparison with Heated Pure Vegetable Oils Available in Vietnam
}

\author{
Anh Tuan Hoang ${ }^{1}$ \\ ${ }^{1}$ Faculty of Mechanical Enginneering, Ho Chi Minh University of Transport, Vietnam \\ Correspondence: Anh Tuan Hoang, Faculty of Mechanical Enginneering, Ho Chi Minh University of Transport, \\ No.2, D3 Road, Ward 25, Binh Thanh District, Ho Chi Minh city, Vietnam. Tel: 84-904-317-584. E-mail: \\ anhtuanhoang1980@gmail.com
}

Received: December 12, 2016

doi:10.5539/jsd.v10n2p93

\author{
Accepted: January 17, $2017 \quad$ Online Published: March 30, 2017 \\ URL: https://doi.org/10.5539/jsd.v10n2p93
}

\begin{abstract}
Pure vegetable oils have the greatest promise for alternative fuels for internal combustion engines beside the depletion of conventional petroleum resources. Among various possible options, pure vegetable oils present promising of greener air substitutes for fossil fuels. Pure vegetable oils, due to the agricultural origin, liquidity, ready availability, renewability, biodegradability are able to reduce the $\mathrm{CO} 2$ emissions in the atmosphere. Also, in Vietnam, pure vegetable oils such as soybean oil (SoO100), coconut oil (CO100) and sunflower oil (SuO100) are available. The paper presents the results of using heated pure vegetable oils for diesel engine D243 with

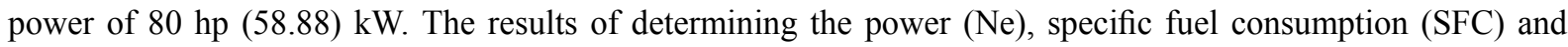
efficiency $(\eta)$ are used to evaluate the performance of engine. The results show that, the engine power $(\mathrm{Ne})$ is $10 \%-15 \%$ lower, the SFC of engine D243 using pure vegetable oils is 3\%-5\% higher and the $\eta$ is $2.5 \%-6.2 \%$ lower compared to diesel oil (DO). Among the pure vegetable oils, the best performance results for D243 diesel engine are obtained from heated pure sunflower oil up to $135^{\circ} \mathrm{C}$.
\end{abstract}

Keywords:heating method, efficiency, specific fuel consumption, power, alternative fuel

\section{Introduction}

Pure vegetable oils that are one of biofuels have turned into more interesting in recent times because of their environmental benefits and renewable ability. Using of pure vegetable oils as alternative fuels for diesel engines is not a new conception and view. As the design, invention, fabrication of the diesel engines, the diesel engine development has been based on the availability of fossil fuel-derived-petroleum to satisfy the needs of the current diesel engines. During this period, the empirical test has been carried out and developed sharply in order to serve the database for the diesel fuel specifications.

The concept of biofuels and the pure vegetable oils fuel has been reintroduced during periods of shortage, crisis and high price of petroleum. Rudolph used peanut oil to fuel his engines in Paris in 1900s, Hemmerlein concluded that the physical and chemical properties of rapeseed oil as a fuel are very similar to those of diesel fuel. Presently, some researches from A.Corsini et al, (2015), R.Altin et al, (2001) and Shay et al, (1993) show that, nearly $0.7 \%$ of worldwide diesel fuels gain from pure vegetable oils. To use vegetable oils as fuel, some different processes is necessary to promote the properties for atomization, mixture and combustion purposes such as pyrolysis of Wiggers.V et al, (2009), catalytic cracking of Nam.L et al, (2011) and heating method of Sagar.P et al, (2010). Generally, as reported from researches, vegetable oils have comparable chemical and physical properties to diesel fuel. However, Murugesan.A et al, (2009) and Ramachandra.T et al, (2004) also concluded due to higher density of vegetable oils around $12 \%$ and around $10 \%$ of lower calorific value than diesel fuel make $4-8 \%$ higher of the specific fuel consumption for conventional diesel. Besides, the cetane number of most vegetable oils is $10-20 \%$ lower than that of diesel fuel as Crookes.C et al, (2006) and Hossain A.K et al, (2010). Kinematic viscosity, surface tension of vegetable oils, which is much higher than those of diesel fuel, are some important characteristics to consider Sigar.P et al, (2008), Giannelos.P et al, (2002). The nozzle coking, deposits in combustion chamber, ring sticking, dilution of lubricating oil occur because of inaccuracy injection and poor atomization characteristics that can be known and explained by higher viscosity, higher surface tension and higher density of pure vegetable oils compared to fossil diesel fuel. Further, the other theories can be used to explain the durability problems of engine and the corrosion of fuel system that the 
chemical properties of pure vegetable oils are much different from diesel fuel. All of these problems may be correlated to incomplete combustion of pure vegetable oils. Obviously, if pure vegetable oils are well mixed with gas in combustion chamber and burned in regions away from injector and the cylinder walls, these problems will not occur and appear. Hence, the researchers hypothesized that above occurrence would coincide with the decreases in combustion efficiency and thermal efficiency. Further, the researchers hypothesized and assumed that the differences in the molecular structures between pure vegetable oils and traditional diesel fuel, mainly the content of unsaturation acids or double bonds of carbon $(\mathrm{C}=\mathrm{C})$, effect on the performance of diesel engine. It is seen basically that, the different theories are used to explain the reason of the various durability problems in diesel engines fueled with vegetable oils. They are suggested: The high viscosity, high surface tension and density of the vegetable oils results in difficulty of fuel spray, atomization, breakup and mixture; The effect of chemical structure of vegetable oils on the combustion chemistry; The incomplete combustion of the vegetable oils occur either spray characteristic such as or chemical reaction. The incomplete subsequent reaction and breakup the droplet of vegetable oils can lead the partial combustion products in the combustion chamber. Effects of the mentioned characteristics of vegetable oils on diesel engine performance have been investigated and studied in some research works.

Most of evidences and researches indicate that the high viscosity, surface tension and density of the vegetable oils are the main causes controlling the start of spay progress, atomization, breakup, mixture and combustion in diesel engine. The high viscosity, surface tension and density of the vegetable oils are also considered as the cause of the discrepancies of the cetane number that is an actual measure of the fuel ignition quality in combustion chamber. With high viscosity, surface tension and density of vegetable oil fuels, the degree of atomization will certainly decrease, leading a longer ignition delay time. Hence, it is necessary to heat vegetable oils up to the most suitable temperature in order to reduce high viscosity, surface tension and density and meet the requirements of fuel used in diesel engine. The paper uses the heating method to evaluate the impact of heated pure vegetable oils at different temperature on the power $(\mathrm{Ne})$, specific fuel consumption (SFC) and efficiency $(\eta)$.

\section{Materials and methods}

Vegetable oils with main content of triglycerides are extracted from the plants and seeds. Physical properties of some selected pure vegetable oils such as pure coconut oil (CO100), pure sunflower oil (SuO100) and pure soybean oil (SoO100) are available in Vietnam and given in Table 1.

Table 1. Physical properties of pure vegetable oil samples and diesel fuel at $30^{\circ} \mathrm{C}$

\begin{tabular}{lcccc}
\hline \multirow{2}{*}{ Fuels } & \multicolumn{4}{c}{ Physical properties } \\
\cline { 2 - 5 } & $\mu\left(\mathrm{mm} / \mathrm{s}^{2}\right)$ & $\sigma(\mathrm{N} / \mathrm{m})$ & $\rho\left(\mathrm{g} / \mathrm{cm}^{3}\right)$ & $\mathrm{CN}$ \\
\hline Coconut (CO100) & 37.5 & 0.034 & 0.903 & 39 \\
Sunflower (SuO100) & 36.3 & 0.033 & 0.901 & 40 \\
Soybean (SoO100) & 40.8 & 0.035 & 0.905 & 38 \\
Diesel fuel & 5.0 & 0.027 & 0.850 & 46 \\
\hline
\end{tabular}

Table 1 shows that, the properties of selected pure vegetable oils are not different much from diesel fuel, such as cetane number is about $8 \%-12 \%$ lower and kinematic viscosity at $30^{\circ} \mathrm{C}$ is about $7-10$ times, density is about $12 \%-15 \%$ and surface tension is $6-10 \%$ higher than those of diesel fuel. Hence, it is absolutely to use pure vegetable oils directly as a fuel in diesel engines that only improving the disadvantages of pure vegetable oils.

\subsection{Physical Properties of Pure Vegetable Oils}

Kinematic viscosity $(\mu)$ is the quantity shown the resistance to the flow of liquid. The higher the viscosity is, the more unfavorable the use is because it reduces the possibility of dispersing while injection into the combustion as well as increasing the ability of the sedimentation in the equipment. Parallel, surface tension $(\sigma)$ is considered as the force applied in the surface plane per unit length. As a result, with high surface tension and viscosity of the fuel, the mist injection and atomization will be less hence these adversely affect the combustion quality and emission characteristics in diesel engines. Moreover, the relationship between density and temperature is similar to surface tension and viscosity. Surface tension is proportional to viscosity, density and inversely proportional to temperature. Relationship between kinematic viscosity, surface tension of selected pure vegetable oils and temperature are shown in Figure 1, Figure 2 and Figure 3. 


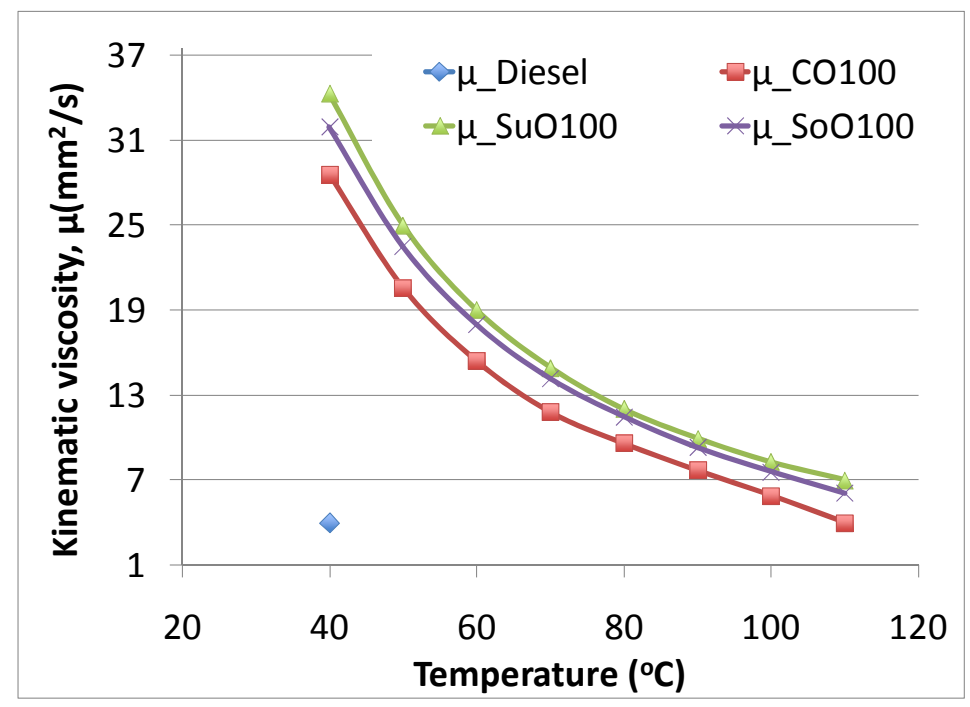

Figure 1. Relationship between kinematic viscosity and temperature

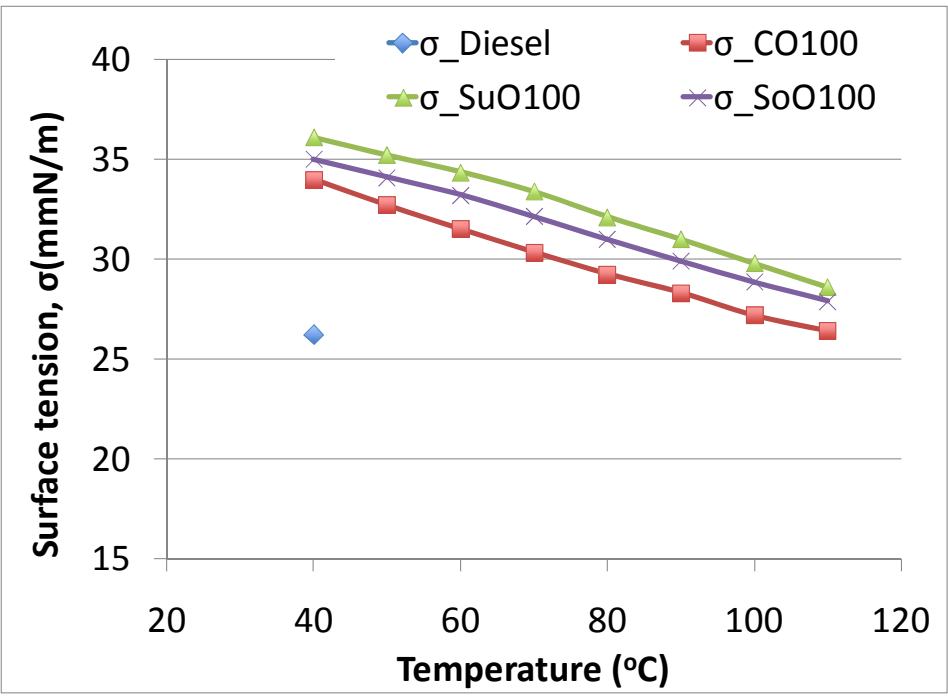

Figure 2. Relationship between surface tension and temperature

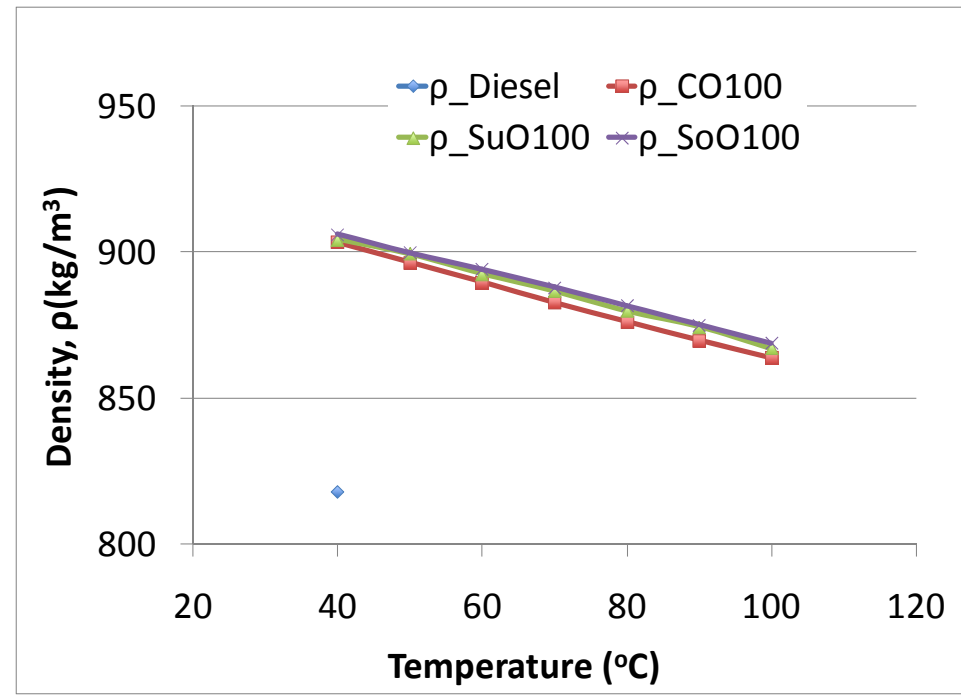

Figure 3. Relationship between density and temperature 
Figure 1, Figure 2 and Figure 3 show that, the most appropriate heating temperature for selected pure vegetable oils $\mathrm{SuO} 100, \mathrm{SoO} 100$ and $\mathrm{CO} 100$ in order to their kinematic viscosities, surface tension meet the requirements of diesel fuel standard are respectively $135^{\circ} \mathrm{C}$ (signed SuO100_t135), $120^{\circ} \mathrm{C}$ (signed SoO100_t120) and $110^{\circ} \mathrm{C}$ (signed CO100_t110). However, this heating temperature, their densities is 3\%-5\% higher than that of diesel fuel. Thus, above heated pure vegetable oil samples such as SuO100_t135, SoO100_t120 and CO100_t110 are used as alternative fuel in test diesel engine and to compare to diesel fuel.

\subsection{Determination Method of SFC}

Diesel engine D243 uses an outside storage tank, which is placed on an accuracy balance, and a digital timer makes sure the mass flow of fuel $\mathrm{M}$ on the diesel engine for the duration of performance test. Above work and equipment installation is to determine the diesel engine SFC via M. The mass flow of fuel M is calculated as the Eq. (1):

$$
M=\frac{M_{i}-M_{f}}{t}
$$

The SFC of diesel engine is considered as fuel mass fueled engine to get $1 \mathrm{~kW}$ of power in an hour. Therefore, it is calculated via $\mathrm{M}$ and engine power $\left(\mathrm{N}_{\mathrm{e}}\right)$ as Eq. (2):

$$
S F C=\frac{3600 M}{N_{e}} 10^{3}
$$

\subsection{Determination Method of Efficiency ( $\eta$ )}

The HHV of a fuel is defined as the total of heat released at $25^{\circ} \mathrm{C}$ by a particular quantity while it is burnt and the products are returned at $25^{\circ} \mathrm{C}$, which considers the implicit heat of water vaporization for the products of combustion. HHV is determined by experiment of physical method, which the pure vegetable oils samples are put in the combustion chamber for combusting completely. Besides, HHV is evaluated by chemical method through Saponification value (SV) and Iodine value (IV). AOCS CD3-1993 standard test method is used to measure the SV of pure vegetable oils samples, and the less SV of an oil is, the more the molecular weight is. Moreover, the molecular weight of vegetable oil is directly proportional to the percentages of $\mathrm{C}$ and $\mathrm{H}$ and therefore, the SV results in decreasing in the heat content of vegetable oils. AOCS CD1-25-1993 standard test method is used to measure the IV of pure vegetable oils samples, the IV much belongs to chemical structure such as double bond $(\mathrm{C}=\mathrm{C})$. Similarly, to the SV, the vegetable oil heat content dramatically depends on the IV. According to chemical point, the HHV of pure vegetable oil samples can be calculated via the SV and the IV as Eq. (3), which was proposed by Demirbas et al, (1998):

$$
H H V=49.43-0.041 S V-0.015 I V
$$

Therefore, HHVs of selected pure vegetable oil samples are shown in Table 2.

Table 2. HHV of pure vegetable oil samples compared to diesel fuel

\begin{tabular}{lcccc}
\hline \multirow{2}{*}{ Fuels } & \multicolumn{4}{c}{ Physical properties } \\
\cline { 2 - 5 } & IV & SV & HHV & HHV $^{*}$ \\
\hline Coconut (CO100) & 70.40 & 218.2 & 39.42 & 39.5 \\
Sunflower (SuO100) & 132.32 & 191.7 & 39.58 & 39.6 \\
Soybean (SoO100) & 69.82 & 220.8 & 39.33 & 39.4 \\
Diesel fuel & & & & 41.0 \\
\hline
\end{tabular}

*: HHV is determined by experiment

Table 2 shows the small difference between physical HHVs and chemical HHVs. Thus, the SVs and IVs of the vegetable oils can be used to calculate their HHVs. The LHV of fuel shows the energy efficient released by combusting a particular quantity of fuel mass unit and the products are returned at $25^{\circ} \mathrm{C}$, which not considers the implicit heat of water vaporization for the products of combustion. In the view of Volpato et al, (2009), the relationship between LHV and HHV is proposed as Eq. (4).

$$
L H V=H H V-3.052
$$

In the diesel engine, the efficiency $(\eta)$ communicates the conversion rate of fuel energy (Q) in combustion to 
obtained power $\left(\mathrm{N}_{\mathrm{e}}\right)$. The fuel energy $(\mathrm{Q})$ in combustion is proposed as Eq. (5):

$$
Q=M . L H V
$$

Moreover, $(\mathrm{Ne})$ is also obtained through equation (2), therefore the $\eta$ can be calculated through LHV and SPC as Eq. (6).

$$
\eta=\frac{N_{e}}{10^{3} Q}=\frac{N_{e}}{10^{3}(M)(L H V)}=\frac{3600}{(S F C)(L H V)}
$$

\section{Materials and Methods}

\subsection{Experimental Set-Up}

The performance tests are carried out by using the diesel engine with $58.88 \mathrm{~kW}(80 \mathrm{hp})$. The specifications of the diesel engine D243 can be described in Table 3.

Table 3. Specifications of diesel engine D243

\begin{tabular}{lcc}
\hline Description & Unit & Quantity \\
\hline Rated power & $\mathrm{kW}$ & 58.88 \\
Maximum revolution & $\mathrm{rpm}$ & 2200 \\
Bore & $\mathrm{mm}$ & 110 \\
Stroke & $\mathrm{mm}$ & 125 \\
Diesel fuel consumption & $\mathrm{g} / \mathrm{kW} . \mathrm{h}$ & 248 \\
\hline
\end{tabular}

The engine D243 is fuelled with SuO100_t135, SoO100_t120, CO100_t110 and diesel in the experiment. The operating characteristics of the diesel engine D243 such as power and $\overline{\mathrm{S} F C}$ were recorded while changing load $\left(\% \mathrm{M}_{\mathrm{e}}\right)$ or engine speed $(\mathrm{n})$. The engine was supplied with conditioning lubricant and cooling systems in order to maintain the stability of the testing system. The heating temperature of SuO100, SoO100 and CO100 is maintained automatically by heater controller.

\subsection{Results}

\subsubsection{Power}

The power of the diesel engine D243 at full load running with diesel fuel and SuO100_t135, SoO100_t120 and CO100_t110 is shown in Figure 4. The power of the diesel engine D243 is reduced from 10\% at lower speed to $15 \%$ at around higher speed while using SuO100_t135, SoO100_t120 and CO100_t110 as fuel. This is comparable to the results presented of Sidibé et al, (2010) and Altin R et al, (2001).

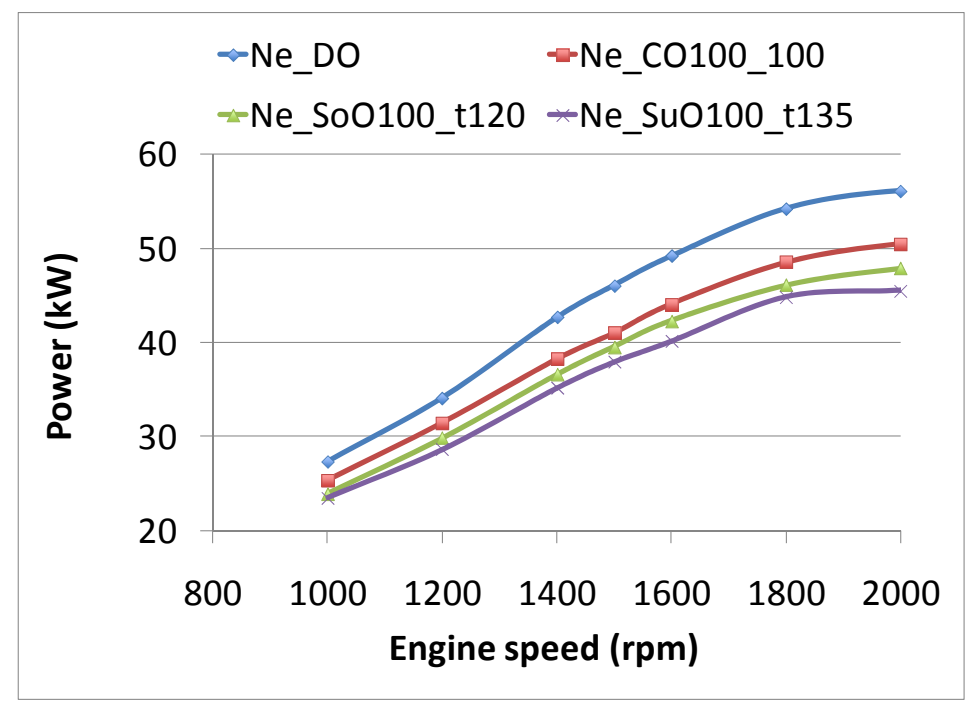

Figure 4. The power of the diesel engine D243 
The lower power of SuO100_t135, SoO100_t120 and CO100_t110 can be explained that SuO100_t135, SoO100_t120 and CO100_t110 have 12\%-15\% lower calorific value compared to diesel fuel. There are not great change in power when the diesel engine D243 running with SuO100_t135, SoO100_t120 and CO100_t110.

\subsubsection{SFC of Engine}

The tests using SuO100_t135, SoO100_t120 and CO100_t110 as fuel in the D243 engine while diesel engine D243 running at full load and different revolution are shown in Figure 5, and while diesel engine D243 running at different loads, at $1500 \mathrm{rpm}$ and $2000 \mathrm{rpm}$ are shown in Figure 6.

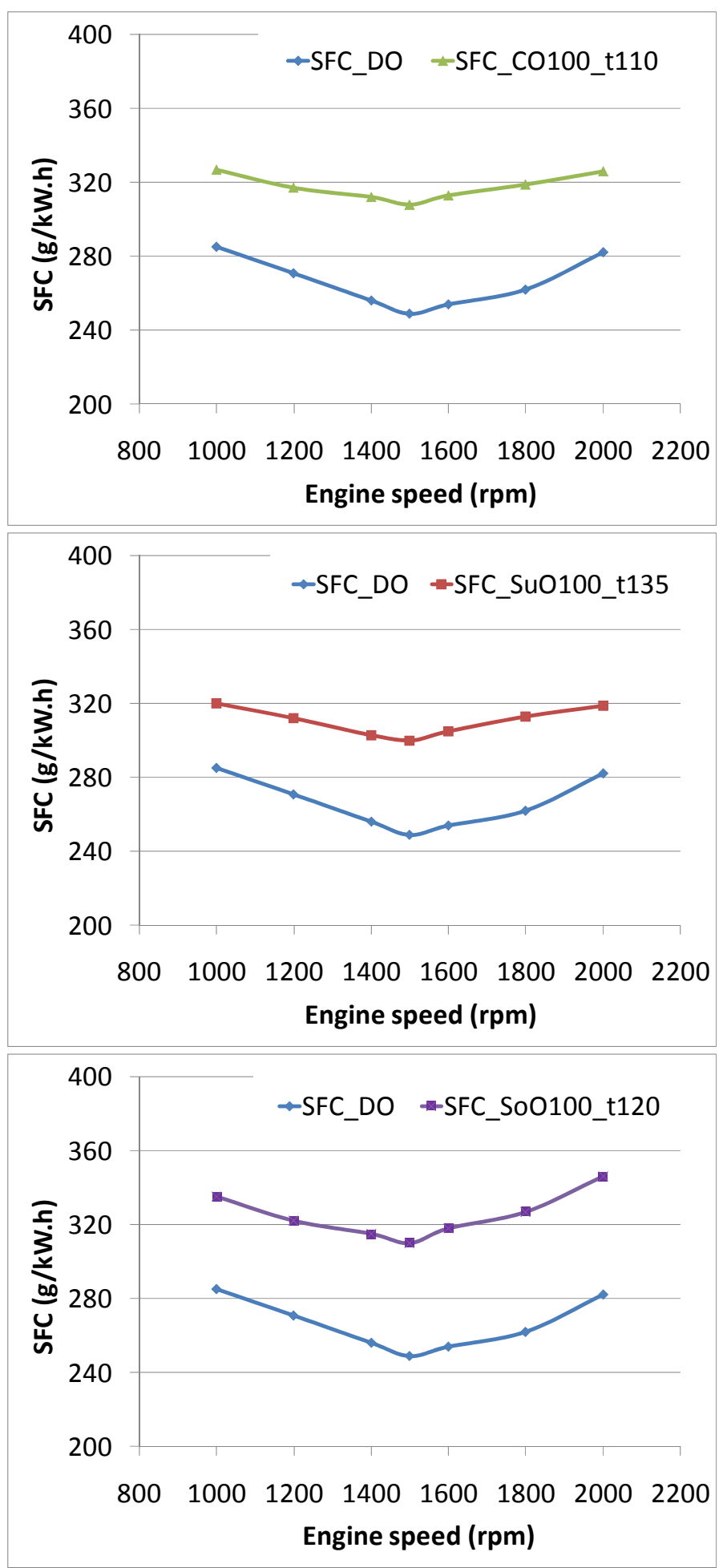

Figure 5. SFC of diesel engine D243 fueled SuO100_t135, SoO100_t120, CO100_t110, diesel oil at full load 
Figure 5 shows that, there is a different behavior of SFC while engine speed increases. It seems that the lowest SFCs reach at around $1500 \mathrm{rpm}$, and they go up when engine speed increases. The SFCs when using SuO100_t135, SoO100_t120 and CO100_t110 as fuel in D243 engine are respectively approximately $16.72 \%$, $20.12 \%$ and $19.15 \%$ higher than diesel fuel SFC. This can be explained due to the lower LHVs of SuO100_t135, SoO100_t120 and CO100_t110 compared to fossil diesel. Related this view, there are some contrary results in the literature, but they were of the same mind that the SFCs as using vegetable oils are higher than that of diesel fuel.

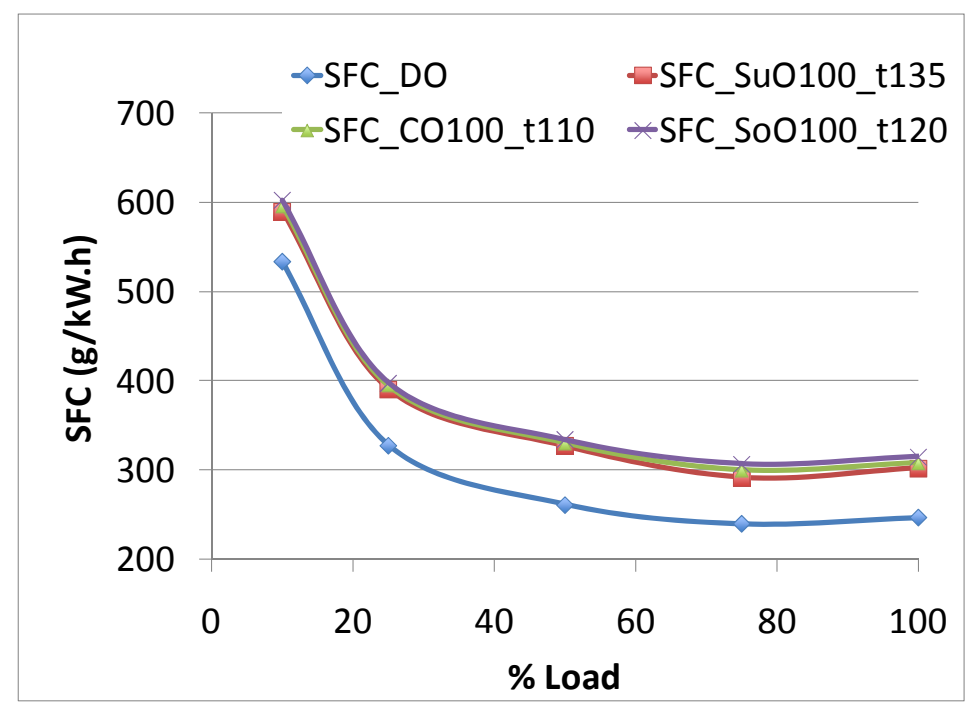

(a)

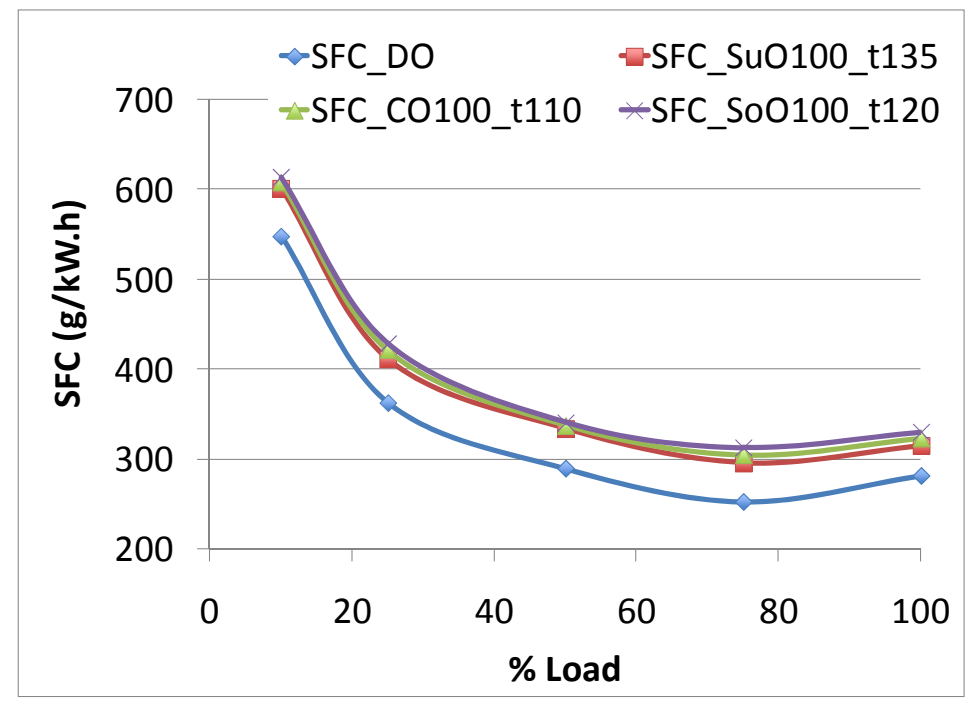

(b)

Figure 6. SFC of diesel engine D243 at $1500 \mathrm{rpm}$ (a) and $2000 \mathrm{rpm}$ (b)

Furthermore, Figure 6 shows that highest SFC of SuO100_t135 is 590.16 g.kW-1 $\mathrm{h}^{-1}$, highest SFC of SoO100_t120

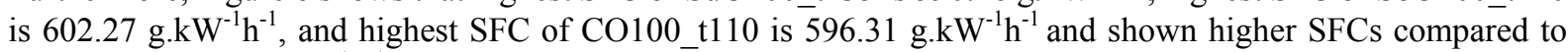
diesel oil $\left(533.75 \mathrm{~g} \cdot \mathrm{kW}^{-1} \mathrm{~h}^{-1}\right)$ at $1500 \mathrm{rpm}$ of engine speed. Similarly, at $2000 \mathrm{rpm}$ of engine speed, highest SFC of SuO100_t135 is 602.35 g.kW $\mathrm{kW}^{-1} \mathrm{~h}^{-1}$, highest SFC of SoO100_t120 is 617.71 g.kW $\mathrm{kW}^{-1} \mathrm{~h}^{-1}$, and highest SFC of CO100_t110 is 608.44 g.kW $\mathrm{kW}^{-1} \mathrm{~h}^{-1}$ and shown higher SFCs compared to diesel oil DO $\left(548.32 \mathrm{~g} \cdot \mathrm{kW}^{-1} \mathrm{~h}^{-1}\right)$. On the average, the SFCs of D243 engine while fueled with SuO100_t135, SoO100_t120 and CO100_t110 increase respectively $19.83 \%, 23.55 \%$ and $21.69 \%$ at $1500 \mathrm{rpm} ; 11.86 \%, 15.01 \%$ and $13.61 \%$ at $2000 \mathrm{rpm}$.

The increase of SFCs due to HHVs of SuO100, SoO100 and CO100 are 7\%-10\% lower than that of diesel fuel. The heating method is only to improve the kinematic viscosity, density and surface tension without changing HHV or 
LHV. The differences between kinematic viscosity and surface tension of pure vegetable oils and diesel oil may be important factors for the performance of diesel engine because of poor atomization, evaporation, mixture into the combustion chamber, therefore occurring incomplete combustion while diesel engine run at low and medium speeds. Further, the differences of densities (densities of selected heated pure vegetable oils are still $5-10 \%$ higher than that of diesel fuel) can also affect engine SFC resulting in different masses although constant volumes with injecting although $\mathrm{SoO} 100, \mathrm{SuO} 100, \mathrm{CO} 100$ are heated up to the most suitable temperature but at these heating temperature, the densities of samples are still 3\%-5\% higher than that of diesel fuel. Hence, they lead higher SFCs compared to diesel fuel.

\subsubsection{Efficiency}

Generally, the engine efficiency $(\eta)$ while fueled SuO100_t135, SoO100_t120 and CO100_t110 at fuel load and different revolution are shown in Figure 7.

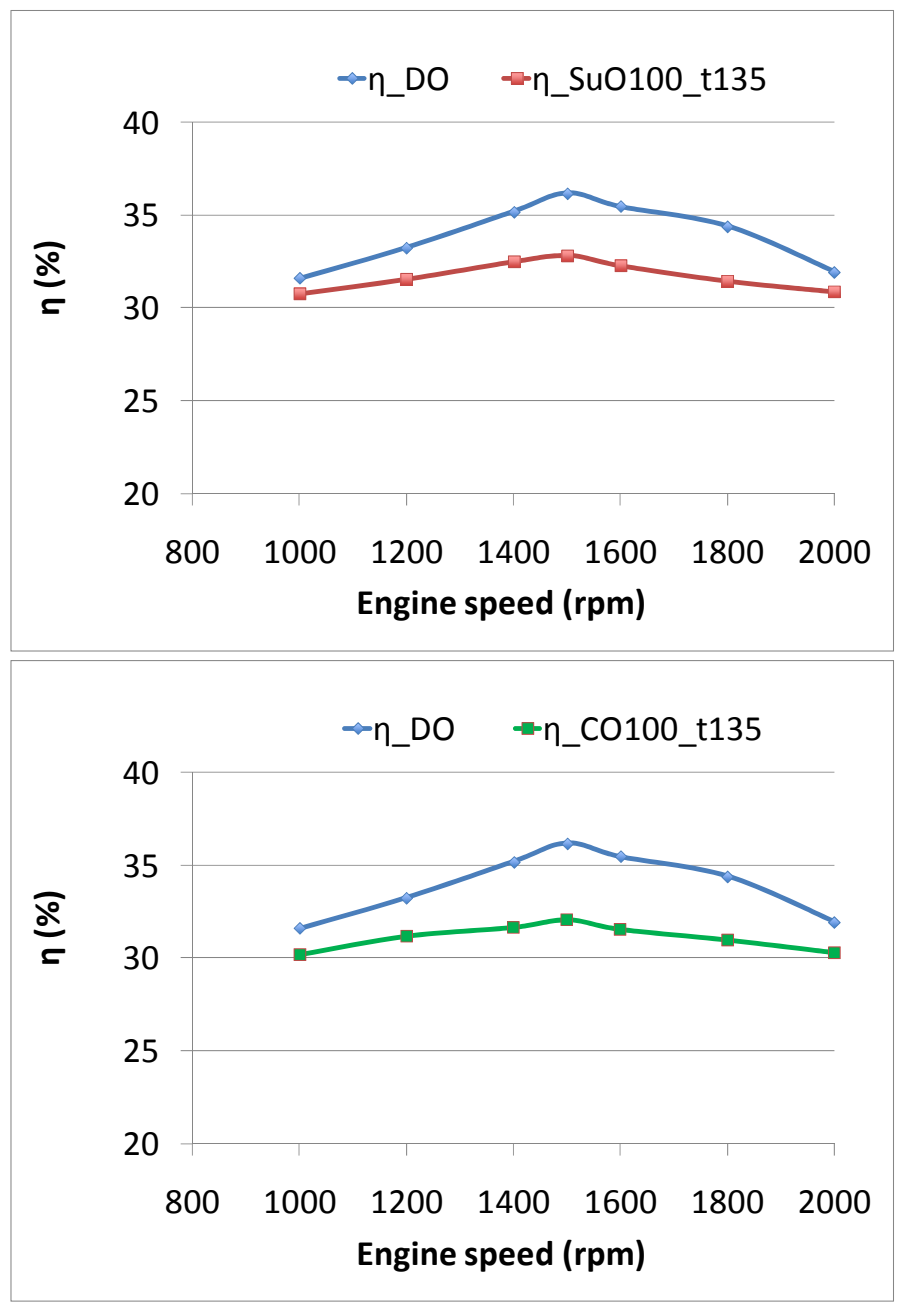




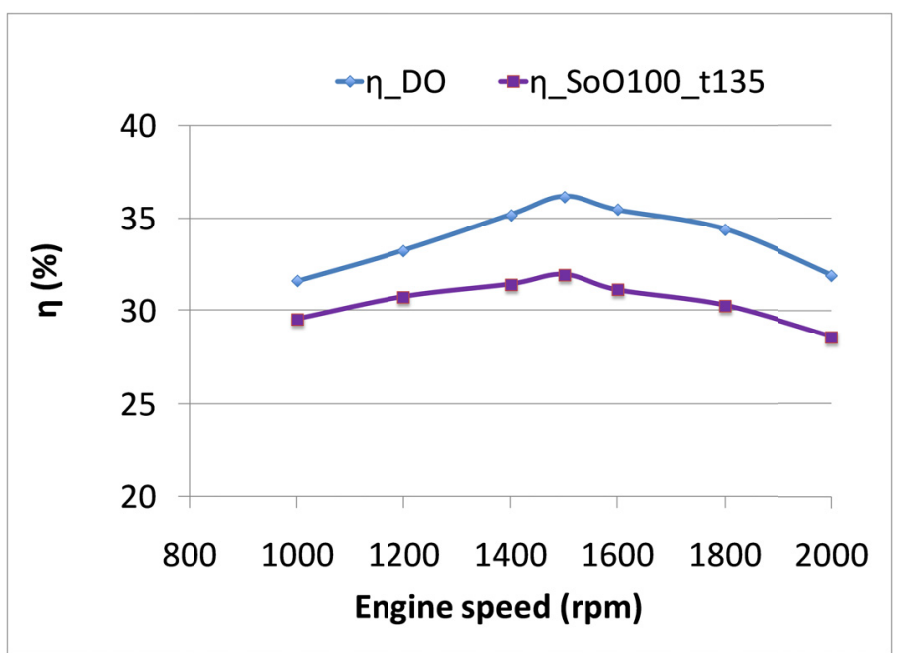

Figure 7. Efficiency $(\eta)$ of diesel engine D243

Figure 7 shows that, the maximum efficiency $(\eta)$ for the D243 engine is obtained at full load and $1500 \mathrm{rpm}$ of engine speed for all test fuels. The maximum D243 engine efficiency is $38.1 \%$ while using diesel fuel. Beside, among the test pure vegetable oils, the higher efficiency level is $32.83 \%$ for SuO100_t 135 , and is $31.95 \%$ for SoO100_t135 and is $32.07 \%$ for CO100_t110. Hence, the overall efficiency abatement of D243 diesel engine using the test pure vegetable oils is $2.5 \%-6.2 \%$. On the average, the $\eta$ of engine fueled SuO100_t135, SoO100_t135, CO100_t110 reduces respectively 2.51\%-5.24\%, 3.72\%-6.2\%, 3.08\%-6.03\%. Generally, the best performance of test pure vegetable oils for D243 diesel engine are obtained while using heated pure sunflower oil up to $135^{\circ} \mathrm{C}$ as fuel.

\section{Conclusion}

The air and water-face pollution is ever-increasing, the depletion of fossil fuel are the urgent matter. However, the pure vegetable oils resources in Vietnam are very abundant. Hence, using pure vegetable oils in order to replace the fossil fuel by step is specially paid attention by Vietnamese Government. The results of this paper show that, the technical and economic indicators of the diesel engine D243 when used SuO100_t135, SoO100_t120 and CO100_t110 directly as fuel are no many changes. When the diesel engine D243 is operated at full load, the engine power $(\mathrm{Ne})$ is about $10 \%$ to $15 \%$ less; the SFCs are approximately $16.72 \%, 20.12 \%$ and $19.15 \%$ higher; the engine efficiency $(\eta)$ is about $2.5 \%$ to $6.2 \%$ less than those of diesel fuel due to their HHVs are lower but densities are higher than those of diesel fuel. Among test pure vegetable oils, the best performance of D243 engine is obtained while fueled SuO100_t135.

\section{Nomenclature}

$\begin{array}{lll}\text { HHV } & \text { Higher heating value } & \mathrm{MJ} \cdot \mathrm{kg}^{-1} \\ \text { LHV } & \text { Lower heating value } & \mathrm{MJ}_{\mathrm{kg}}{ }^{-1} \\ \mathrm{CN} & \text { Cetane number } & \\ \mu & \text { Kinematic viscosity } & \mathrm{mm} \cdot \mathrm{s}^{-1} \\ \sigma & \text { Surface tension } & \mathrm{mN} \cdot \mathrm{m} \\ \mathrm{D} & \text { Density } & \mathrm{g} \cdot \mathrm{cm}^{-3} \\ \mathrm{M} & \text { Fuel mass flow } & \mathrm{kg} \cdot \mathrm{s}^{-1} \\ \mathrm{M}_{\mathrm{i}} & \text { Fuel mass at beginning } & \mathrm{kg} \\ \mathrm{M}_{\mathrm{f}} & \text { Fuel mass at the end } & \mathrm{kg} \\ \mathrm{t} & \text { Test time } & \mathrm{s} \\ \mathrm{SFC} & \text { Specific fuel consumption } & \mathrm{g} \cdot \mathrm{kW}^{-1} \mathrm{~h}^{-1} \\ \mathrm{~N}_{\mathrm{e}} & \text { Engine power } & \mathrm{kW} \\ \mathrm{Q} & \text { Fuel energy released in combustion } & \mathrm{MW} \\ \eta & \text { Efficiency } & \end{array}$




\section{Acknowledgements}

The authors acknowledge Ho Chi Minh University of Transport, School of Transportation Engineering - Hanoi University of Science and Technology, National Key Laboratory for Refining and Petrochemical Technologies for supporting this research.

\section{References}

Altin, R. et al. (2001). The potential of using vege-table oil fuels as fuel for diesel engines.Energy Conversion and Management, 42(5), 529-538. http://dx.doi.org/10.1016/S0196-8904(00)00080-7

Corsini,A. et al. (2015).Vegetable Oils as Fuels in Diesel Engine. Engine Performance and Emissions, 81, 942949. http://dx.doi.org/10.1016/j.egypro.2015.12.151

Crookes, C. et al. (2006). Comparative bio-fuel performance in internal combustion engines.Biomass and Bioenergy, 30(5), 461-468. http://dx.doi.org/10.1016/j.biombioe.2005.11.022

Demirbas, A. et al. (1998). Fuel properties and calculation of higher heating values of vegetable oils.Fuel, 11171120. http://dx.doi.org/10.1016/S0016-2361(97)00289-5

Dykstra et al. (1988). Diesel fuel from thermal decomposition of soybean oil.J Am Oil Chem Soc, 65, 1781-1785.

Giannelos, P.N. et al. (2002).Tobacco seed oil as an alternative diesel fuel: Physical and chemical properties, Ind Crop Prod 16, pp.1-9. http://dx.doi.org/10.1016/S0926-6690(02)00002-X

Hossain, A.K. et al. (2010). Plant oils as fuels for compression ignition engines: a technical review and life-cycle analysis.Renewable Energy, 35(1), 1-13. http://dx.doi.org/10.1016/j.renene.2009.05.009

Knothe, G. et al. (1997). The use of vegetable oils and their derivatives as alternative diesel fuels.

Machacon, H.T.C. et al. (2001).The effect of coconut oil and diesel fuel blends on diesel engine performance and exhaust emissions. JSAE Rev, 22, 349-355. http://dx.doi.org/10.1016/S0389-4304(01)00111-4

Misra, R.D. et al. (2010). Straight vegetable oils usage in a compression ignition engine - A review.Renewable and Sustainable Energy Reviews, 14(9), 3005-3013. http://dx.doi.org/10.1016/j.rser.2010.06.010

Murugesan, A. et al. (2009). Biodiesel as an alter-native fuel for diesel engines - A review.Renewable and Sustainable Energy Reviews, 13(3), 653-662. http://dx.doi.org/10.1016/j.rser.2007.10.007

Nam, L. T. H. et al. (2011).Preparation of bio-fuels by catalytic cracking reaction of vegetable oil sludge.Fuel, 90(3), 1069-1075. http://dx.doi.org/10.1016/j.fuel.2010.10.060

Ramachandra, T.V. et al. (2004). Conversion of vegetable oils to alternative diesel-like fuels.Energy Edu Sci Technol, 14, 33-42. http://dx.doi.org/10.1016/0016-2361(87)90184-0

Ramadhas, A.S. et al. (2005). Characterization and effect of using rubber seed oil as fuel in the compression ignition engines.Renewable Energy, 30(5), 795-803. http://dx.doi.org/10.1016/j.renene.2004.07.002

Sagar Pramodrao Kadu etal. (2010). Experimental Investigations on the Use of Preheated Neat Karanja Oil as Fuel in a Compression Ignition Engine.Engineering and Technology, 540-544.

Schwab, A.W. et al. (1987).Preparation and properties of diesel fuels from vegetable oils. Fuel, 66, 1372-1378.

Shay, E. G. et al. (1993). Diesel fuel from vegetable oil - status and opportunities.Biomass and Bioenergy, 4(4), 227-242. http://dx.doi.org/10.1016/0961-9534(93)90080-N

Sidibé, S.S. et al. (2010).Use of crude filtered vegetable oil as a fuel in diesel engines state of the art: Literature review.Renewable and Sustainable Energy Reviews, 14(9), 2748-2759. http://dx.doi.org/10.1016/j.rser.2010.06.018

Sigar, C.P. et al. (2008). Performance and emission characteristics of vegetable oil as diesel fuel extender. Energy Sources, Part A: Recovery, Utilization, and Environmental Effects, Vol.31, No.2, pp.139-148. http://dx.doi.org/10.1080/15567030701513160

Volpato CES et al. (2009). Desempenho de motor diesel quatro tempos alimentado com biodiesel de oleo de soja (B100).Ciencia Agrotecnologica, 33(4), 1125-30. http://dx.doi.org/10.1590/S1413-70542009000400025

Wiggers, V.R. et al. (2009).Biofuels from continuous fast pyrolysis of soybean oil: a pilot plant study. Bioresource Technology, 100(24), 6570-6577. http://dx.doi.org/10.1016/j.biortech.2009.07.059 


\section{Copyrights}

Copyright for this articleis retained by the author(s), with first publication rights granted to the journal.

This is an open-access article distributed under the terms and conditions of the CreativeCommons Attribution license (http://creativecommons.org/licenses/by/4.0/). 